\title{
DIABETIC FOOT CARE KNOWLEDGE AND ITS ASSOCIATED FACTORS AMONG TYPE 2 DIABETES PATIENTS
}

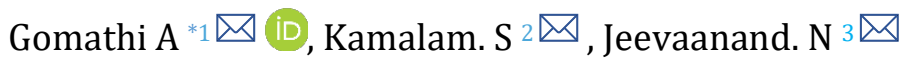 \\ ${ }^{1}$ Associate Professor, College of Nursing, AIIMS, Jodhpur, India \\ ${ }^{2}$ Professor cum Principal, AG Padmavathi College of Nursing, Puducherry, India \\ 3 Medical Officer (Ayurveda) Primary Health Centre, Ariyur, Puducherry, India
}

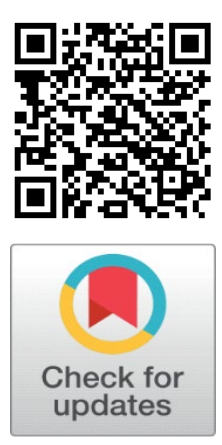

Received 28 July 2021

Accepted 11 August2021

Published 31 August 2021

\section{CorrespondingAuthor}

Gomathi A,

arumugamg@aiimsjodhpur.edu.in

DOI

10.29121/granthaalayah.v9.i8.2021. 4159

Funding: This research received no specific grant from any funding agency in the public, commercial, or not-for-profit sectors.

Copyright: (C) 2021 The Author(s). This is an open access article distributed under the terms of the Creative Commons Attribution License, which permits unrestricted use, distribution, and reproduction in any medium, provided the original author and source are credited.

\section{ABSTRACT}

Background: Diabetes is traditionally known as a "silent disease," exhibiting no symptoms until it progresses to severe target organ damage.

Aims \& Objective: The study was conducted to determine the knowledge of foot care, knowledge regarding foot care practice and its associated factors among type 2 diabetes patients.

Material and Methods: A Community based cross-sectional study was conducted at a primary health centre, Pondicherry, 107 subjects were selected by convenience sampling technique. Data was collected from December 2020 to March 2021, among type 2 diabetes who attended the diabetic clinic. A validated pretested questionnaire was used to assess the knowledge of foot care, knowledge regarding foot care practice and its associated factors among type 2 diabetes patients. Data was analysed using SPSS 21.

Results: Among 107 diabetes patients $70.1 \%$ of them had poor knowledge in foot care and $28 \%$ of them had poor Knowledge regarding practice of foot care. There was highly significant $(\mathrm{p}<0.001)$ relationship between knowledge of foot care and Knowledge regarding Practice of foot care. There was highly significant association $(\mathrm{p}<0.05)$ between the knowledge of foot care with selected demographic variables of gender, occupation, alcohol consumption, regularity of treatment and source of information.

Conclusions: It is a need of the hour to conduct health education programme to create awareness among rural people for better glycaemic control and prevention of ulcer foot in type 2 diabetes mellitus patients.

Keywords: Diabetes Mellitus, Knowledge, Practice, and Foot Care

\section{INTRODUCTION}

Type 2 Diabetes mellitus is a common form of Diabetes characterized by hyperglycemia, insulin resistance, and relative insulin deficiency. Interaction between genetic, environmental and behavioral risk factors, more vulnerable to complications, leading to their premature death. Insidious onset and late recognition, leads to increased morbidity and mortality especially in poor resource developing countries. Nicolucci A, Kovacs Burns K, Holt RIG, Comaschi M, Hermanns N, Ishii H, et al. 2013

Currently around 40.9 million is expected to rise to 69.9 million by 2025 unless urgent preventive steps are taken "more prone to premature coronary artery disease. India - "diabetes capital of the world". Mohan.V, Sandeep.S, Deepa.R, Shah.B, Varghese.C. 2007 
WHO estimated that diabetes will be one of the leading cause of death in the world by 2030? Mathers CD, Loncar D. 2006 Globally every year more than I million limbs are lost due to diabetes. WHO. 2016 The diabetic foot ulcer prevalence was 8$17 \%$ and leads to lifelong disability, repeated, prolonged hospitalization, financial crisis to the families and health care system. Stockl K, Vanderplas A, Tafesse E, Chang E. 2004 Half of the diabetic foot ulcer complications happens due to foot infection. Dang CN, Boulton A.J. 2003, Pinzur MS, Slovenkai MP, Trepman E,Shields NN, 2005

Out of pocket expenditure for the treatment of Non communicable disease has increased drastically in people belonging to lower socioeconomically class spend recently Sharma K. 2013. Prevalence estimates of diabetes in India ranges from $5.6 \%$ to $12.4 \%$ in urban areas and $2.4 \%$ to $2.7 \%$ in rural areas. Kurian.B,Qurieshi M.N , Ganesh.R, Leelamon.K. 2016 However there is a remarkable advancement available in the field of diabetology, the disease is doubling at alarming rate and it is having been observed that rural public has very little knowledge about diabetes. Sivapriya.T , John. 2019. Around 6\% of people are affected by foot disease due to infection, ulceration and destruction of foot tissues, can destroy the patient's social life and source of income and $0.03 \%$ to $1.5 \%$ of diabetic patients needed amputation. But most of the foot related complications can be prevented by proper foot screening and foot care. Mishra SC, Chhatbar KC, Kashikar A, Mehndiratta A, 2021

With this view a community-based study was undertaken to assess the knowledge of foot care and knowledge regarding foot care practices among patients with diabetes mellitus.

\section{SUBJECTS AND METHODS}

\subsection{STUDY DESIGN}

A community based cross-sectional study was initiated to assess the knowledge of foot care and knowledge regarding foot care practice and its associated factors among type 2 diabetes patients, visiting the diabetic clinic at Rural Primary Health Centre Puducherry south India, from December 2020 to March 2021.

\subsection{SAMPLE AND SAMPLING METHOD}

Type 2 diabetes clients in the age group of 40-60 years were selected using the convenience sampling method for the study. Both sex were included in the study. Subjects who were non -cooperative, migrants, pregnant women, mental illness, or who were not willing to participate in the study were excluded. Based on the previous study, the expected proportion of people with knowledge regarding diabetic foot care practice was determined to be $62 \%$. The minimum sample size for the study was calculated to be 94 using the following formula $\mathrm{n}=4 \mathrm{pq} / \mathrm{d} 2$ where $\mathrm{p}$ : expected proportion (0.62), Z1-p: alpha error 1.96 (confidence interval 95\%), d: absolute precision (10\%). Asmelash.D, Abdu.N, Tefer.S, Baynes.W.H,Derbew 2019 In this study 107 subjects included. 


\subsection{QUESTIONNAIRE}

In this study, the investigator used a self-developed validated pretested questionnaire to assess the knowledge of foot care, knowledge regarding foot care practice and its associated factors among type 2 diabetes patients.

The questionnaire had two parts. The first part included demographic information on gender, age, education, income and occupation, clinical variables of diabetes mellitus and the second part assessed the study participant's knowledge of foot care, and knowledge regarding foot care practice. The knowledge of foot care section included 20questions regarding foot care. For correct response score 1 was given and the scores are further categorized as "Good knowledge" (Score range: 1520,) "Fair knowledge" (Score range: 11 -14) and the "Poor knowledge" (Score range: $0-10)$. Knowledge regarding foot care practice included 12 questions towards their practice related to foot care and the response options were yes or no. The Scores range from 0-12, comprised three parts, categorized "Good practice" (Score range10-12,), Fair practice" (Score range: 6 -9) and the poor practice " (Score range: $0-5$ ). The tool Validity index score was .8. Before conducting the main study, a pilot study was conducted to check the feasibility, ensure reliability and the validity of the tool for the study.

\section{Data collection procedure}

After explaining about the study and ensuring their confidentiality of the data. Data was collected from December 2020 to March 2021 through semi structured interview technique, guided by a validated pretested questionnaire.

\subsection{ETHICAL APPROVAL OF RESEARCH}

The study was approved by the Institutional Ethics Committee of AG Padmavathi College of nursing Pondicherry, (Ref.no.AGP/IEC/2020/17X007). The participants (40-60 years were informed about the study and given the verbal consent. The participation was voluntary and without compensation. The questions did not involve any personally identifiable information. All the information was kept confidential and used for the purpose of this study only.

\subsection{ANALYTICAL METHODS}

The SPSS version 21 was used to analyse the data. The correlation was analysed by the Pearson correlation coefficient (Knowledge of foot care and knowledge regarding foot care practice) and to determine the association of knowledge with selected demographic variable was analysed by Chi-square test, P-value $<0.05$ was considered statistically significant. 


\section{RESULTS}

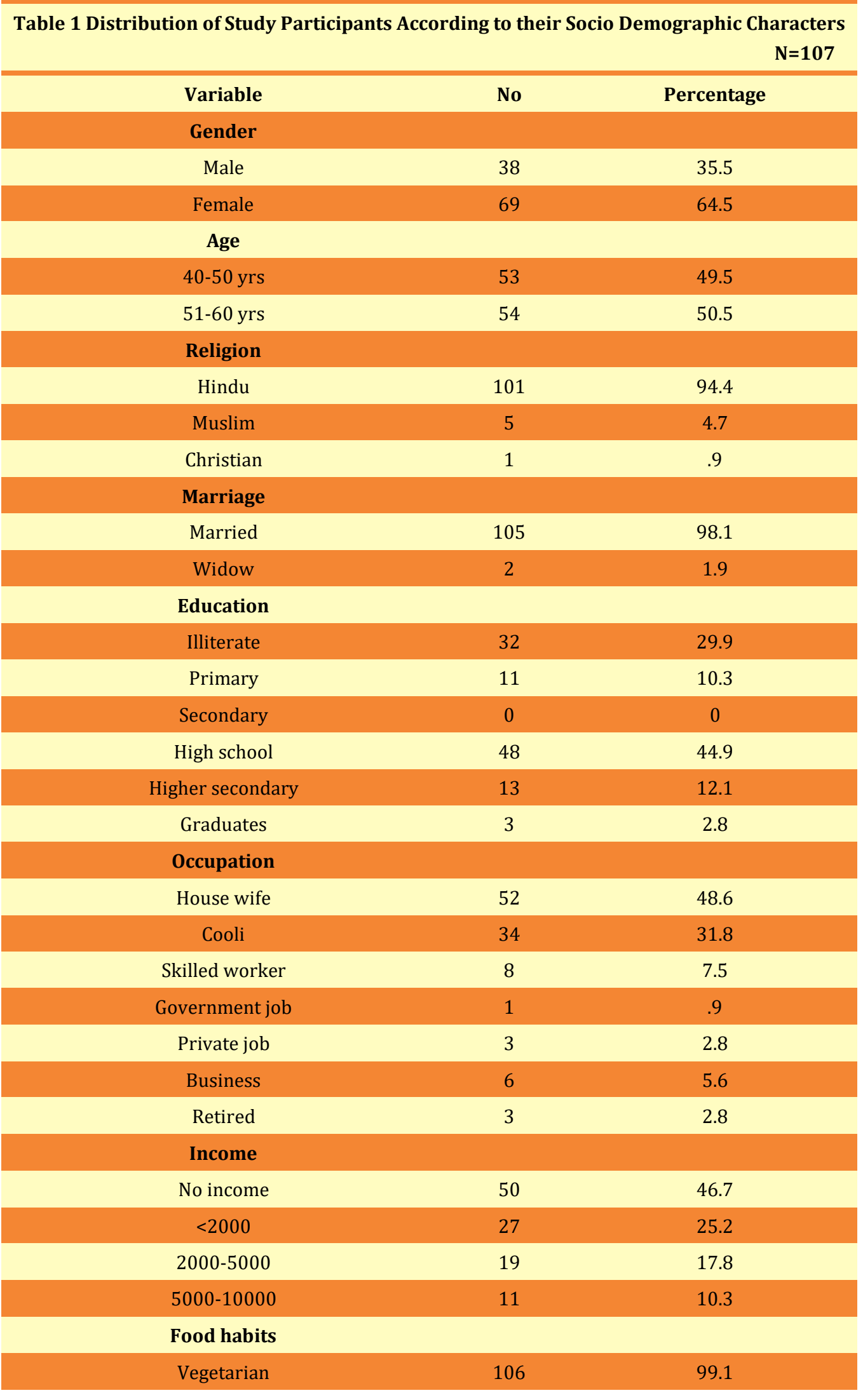


Gomathi A, Kamalam. S, and Jeevaanand. N

\begin{tabular}{ccc}
\hline Non vegetarian & 1 & .9 \\
\hline History of Smoking & 26 & 24.3 \\
Yes & 81 & 75.7 \\
\hline No & & \\
\hline History of Alcohol & 26 & 24.3 \\
\hline Yes & 81 & 75.7 \\
\hline No & & \\
\hline History of Tobacco & 5 & 4.7 \\
\hline Yes & 102 & 95.3 \\
\hline
\end{tabular}

Table 1 shows that Out of the 107 subjects, 107were considered eligible for analysis giving a response rate of $100 \%$. Age wise distribution shows that $50.5 \%$ of them were $>51-60$ years of age. Majority of these diabetic patients belonged to Hindu religion $94.4 \%, 29.9 \%$ of them illiterate, $24.3 \%$ of them having the habits of smoking and alcohol consumption and $4.7 \%$ of them having tobacco habits

Table 2 Characteristics of patients with type 2 diabetes mellitus

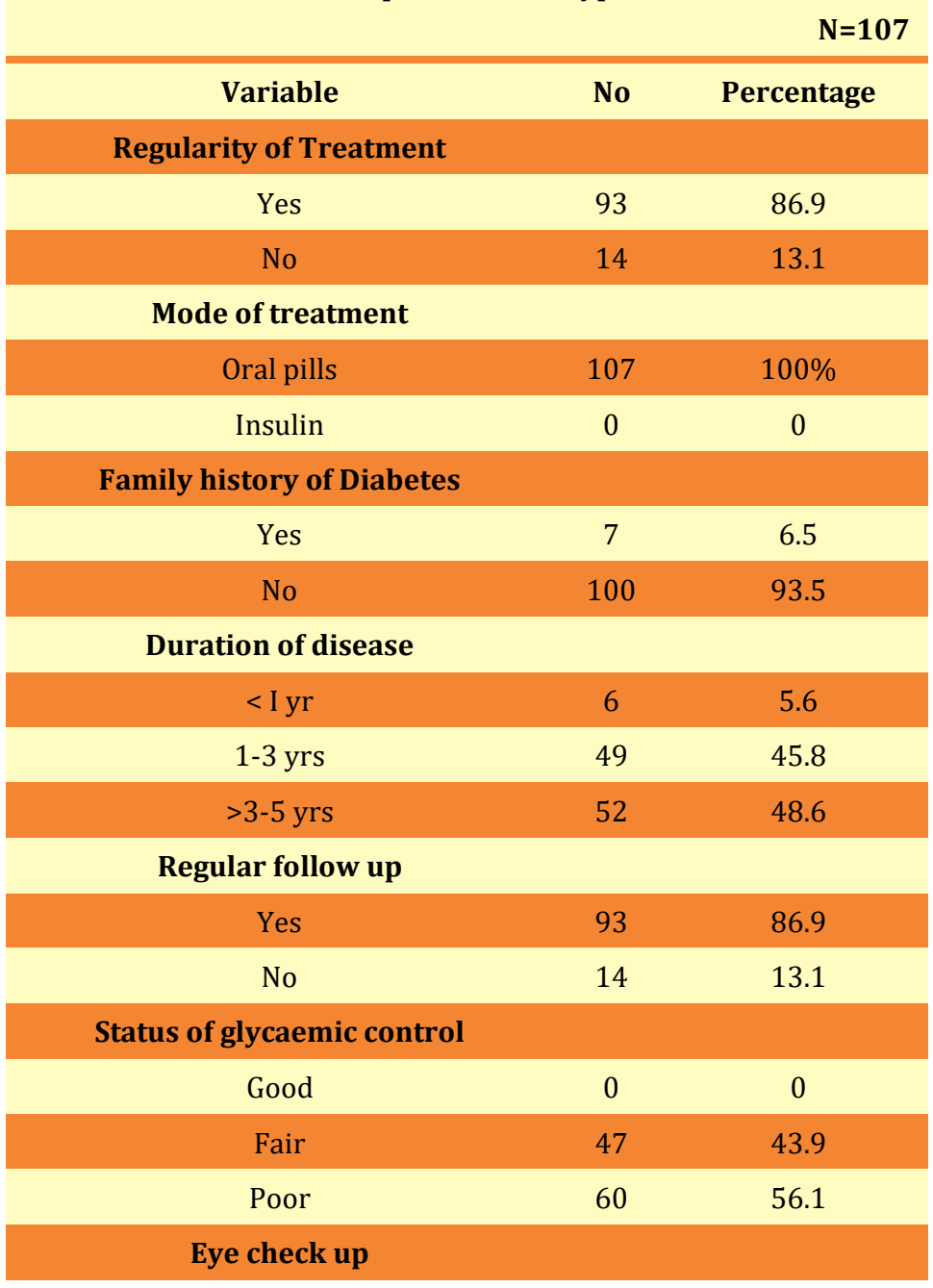




\begin{tabular}{ccc}
\hline Yes & 8 & 7.5 \\
No & 99 & 92.5 \\
\hline Renal check up & & \\
Yes & 2 & 1.9 \\
No & 105 & 98.1 \\
\hline Cardiovascular & & \\
Yes & 19 & 17.8 \\
No & 88 & 82.2 \\
\hline Source of information & & \\
Doctor & 37 & 34.6 \\
Nurses & 40 & 37.4 \\
Media & 20 & 18.7 \\
Relatives & 10 & 9.3 \\
\hline
\end{tabular}

Table 2 shows that out of 107 diabetes patients $86.9 \%$ of them in regular treatment, $6.5 \%$ of them has family history of diabetes mellitus, $48.6 \%$ of them has the history of duration of disease $>3$ to 5 years and $37.4 \%$ of them received source of information from nurses, $86.9 \%$ of them in regular follow up ,56.1\% of them poor glycaemic control, $92.5 \%$ of them did not undergo eye check-up ,91.8\% of them not undergone renal and $82.2 \%$ of them not undergone cardiovascular check-up.

Table 3 Level knowledge and knowledge regarding practice score towards foot care among diabetes patients.

\begin{tabular}{|cccc}
\hline Variable & Good & Fair & Poor \\
\hline Knowledge of foot care & $7(6.5 \%)$ & $25(23.4 \%)$ & $75(70.1 \%)$ \\
\hline $\begin{array}{c}\text { Knowledge regarding Practice of foot } \\
\text { care }\end{array}$ & $30(28 \%)$ & $47(43.9 \%)$ & $30(28 \%)$ \\
\hline
\end{tabular}

Table 3 shows that Among 107 diabetes patients 70.1\%of them had poor knowledge and $28 \%$ of them had poor Knowledge regarding practice of foot care.

\begin{tabular}{|c|c|}
$\begin{array}{l}\text { Table } 4 \text { Mean foot care knowledge and knowledge regarding practice score towards foot care } \\
\text { among diabetes patients. }\end{array}$ & $\begin{array}{c}\mathbf{N = 1 0 7} \\
\text { Variable }\end{array}$ \\
\hline Knowledge of foot care & Mean \pm SD \\
\hline Knowledge regarding Practice & $6.88 \pm 4.39$ \\
\hline Total & $6.87 \pm 2.85$ \\
\hline
\end{tabular}

Table 4 shows that the mean scores of knowledges and practice were $6.88 \pm 4.19,6.87 \pm 2.85$ respectively. The overall mean KP score was $13.75 \pm 7.29$ 
Table 5 Correlation (Pearson) between foot care Knowledge \& Knowledge regarding Practice score towards foot care among Diabetic patients.

$\begin{array}{ccc}\text { Levels } & \text { r value } & \text { p value } \\ \text { Knowledge of foot care \& Knowledge regarding Practice of foot care. } & 0.822 & .000^{*}\end{array}$

Statistically significant at $* * \mathrm{p}<0.01$

Table 5 that there was highly significant $(<0.001)$ relationship between foot care Knowledge \& Knowledge regarding Practice score towards foot care

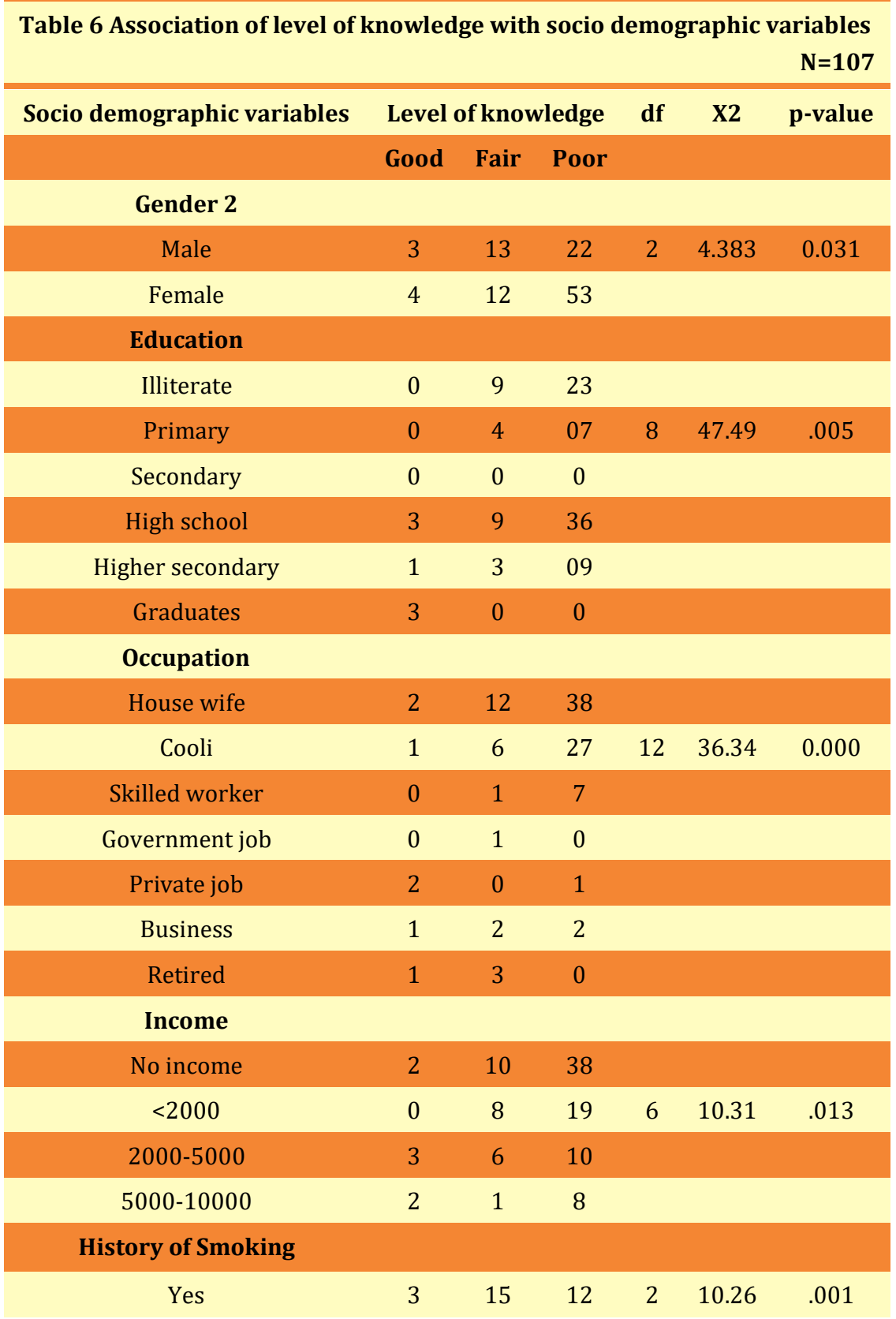




\begin{tabular}{|c|ccccccc|}
\hline $\begin{array}{c}\text { No } \\
\text { History of Alcohol }\end{array}$ & 4 & 10 & 63 & & & \\
\hline Yes & 4 & 17 & 60 & 6 & 2.87 & .036 \\
\hline No & 3 & 8 & 15 & & & \\
\hline Duration of disease & & & & & & \\
\hline < I yr & 1 & 0 & 5 & & & \\
\hline $1-3$ yrs & 2 & 9 & 38 & 4 & 5.72 & .041 \\
\hline$>3-5$ yrs & 4 & 16 & 32 & & & \\
\hline Regular check up & & & & & & \\
\hline Yes & 7 & 16 & 42 & & & \\
\hline No & 0 & 09 & 33 & 2 & 5.343 & .015 \\
\hline Cardiovascular check-up & & & & & & \\
\hline Yes & 7 & 0 & 19 & 2 & 9.857 & .001 \\
\hline No & 0 & 25 & 56 & & & \\
\hline
\end{tabular}

Table 6 shows that that the Association of knowledge with demographic variables revealed that there was highly significant association $(<0.05)$ with gender, education, occupation, income, smoking alcohol consumption, duration of illness regularity of treatment and regular cardio vascular check-up.

\section{DISCUSSION}

This study is intended to illustrate the knowledge and practices of the general public across the various demographic groups of rural people towards type 2 diabetes and identify the socioeconomic factors that affect them. It was observed in our study that $70.1 \%$ of them had poor knowledge, poor practice $28 \%$ towards diabetic foot care. These findings were supported by D.S.D et.al concluded in their study that $27 \%$ of them had poor knowledge and $35 \%$ of them had poor practice towards diabetic foot care D S D., Vincent J., Saju C.R. 2020 and Saurabh S, Sarkar S, Selvaraj K, Kar SS, Kumar SG, Roy G. 2014 who reported in their study that nearly $53 \%$ of them had good knowledge and $44,7 \%$ of them had poor practices towards foot care. Saurabh S, Sarkar S, Selvaraj K, Kar SS, Kumar SG, Roy G. 2014

Another study conducted by Pitchai.P et.al concluded in their study that among rural population only $8 \%$ of them had good Knowledge and $48 \%$ of them had poor practices of diabetic foot care as compared to urban population that $58 \%$ of them had good Knowledge and 6\% of them had poor practices. Pitchai P, Joshi J. 2015

In contrast a study conducted by George $\mathrm{H}$ et all have reported that $75 \%$ of participants had good knowledge and $67 \%$ of them had good practice towards diabetic foot care. George H, Rakesh PS, Krishna M, Alex R, Abraham VJ, George K, et al In this study the overall mean KP score was $13.75 \pm 7.29$. The results concur with those reported by Fatemah $M$ et.al found that most Patients $(79.3 \%)$ had good knowledge, and less than one third of patients (30.8\%) practiced good Diabetic foot care, the mean knowledge score of the respondents was $12.7 \pm 2.7$ and mean practice score was $55.7 \pm 9.2$ and also concluded that knowledge regarding foot care was good and self-foot care practice was satisfactory. F.M. Alsaleh, K.S. AlBassam, Z.K. Alsairafi et al. The result of current study revealed that the highly significant 
$(<0.001)$ relationship between knowledge and practice. These findings in dis agreement with Vighnesh CS, Rangaswamy S, Arthi M. 2019who reported insignificant strong correlation between knowledge and practice of foot care $(\mathrm{r}=$ $0.79)$. In this study knowledge got statistically significant association $(<0.05)$ with significant association $(<0.05)$ with gender, education, occupation, income, smoking alcohol consumption, duration of illness regularity of treatment and regular cardio vascular check-up. A study conducted by George $\mathrm{H}$ et.al reported education and socioeconomic status were significantly associated with knowledge of diabetic care. George H, Rakesh PS, Krishna M, Alex R, Abraham VJ, George K, et al.

In this study Age wise distribution shows that 50.5\%of them were $>51-60$ years of age. Majority of these diabetic patients belonged to Hindu religion $94.4 \%$, $98.1 \%$ of them married, $29.9 \%$ of them illiterate, $24.3 \%$ of them having the habits of smoking and alcohol consumption and $4.7 \%$ of them having tobacco habits. The findings were similar to the study conducted Shrivastava PS et.al Shrivastava PS, Shrivastava SR, Ramasamy J (2015)

Out of 107 diabetes patients $86.9 \%$ of them in regular treatment, $6.5 \%$ of them has family history of diabetes mellitus, $48.6 \%$ of them has the history of duration of disease $>3$ to 5 years and $37.4 \%$ of them received source of information from nurses, $86.9 \%$ of them in regular follow up ,56.1\% of them poor glycaemic control, $92.5 \%$ of them did not undergo eye check-up , $91.8 \%$ of them not undergone renal and $82.2 \%$ of them not undergone cardiovascular check-up.

\section{CONCLUSION}

The study revealed that the knowledge foot care and knowledge regarding foot care practices of diabetic patients were poor. It is an urgent need of the hour to conduct health educational programme to make awareness among rural people for better control and management of the disease.

\section{Availability of data and materials}

All data generated during this study are included in the article. Raw data would remain confidential and would not be shared.

\section{Ethical approval of research}

The study was approved by the Institutional Ethics Committee of AG Padmavathi College of nursing Pondicherry, (Ref.no.AGP/IEC/2020/17X008). The participants (40-60 years were informed about the study and given the verbal consent. The participation in survey was voluntary and without compensation. The survey questions did not involve any personally identifiable information. All the information was kept confidential and used for the purpose of this study only.

\section{ACKNOWLEDGEMENT}

We express our sincere gratitude to the medical officer, staffs of Ariyur primary health centre and all the participants for taking part in the survey. 


\section{REFERENCES}

Asmelash.D, $\quad$ Abdu.N, $\quad$ Tefer.S, $\quad$ Baynes.W.H,Derbew 2019. Cherie.Knowledge,Attitude,and Practice towards glycaemic control and its Associated Factors among Diabetes Mellitus Patients, Journal of Diabetes Research.1-9.https://doi.org/10.1155/2019/2593684.. Accessed on May 11th. Retrived from https://doi.org/10.1155/2019/2593684

D S D., Vincent J., Saju C.R. 2020; Knowledge, Attitude and Practice of Diabetic Patients about Their Foot Care in Rural Thrissur, Kerala. Journal of Medical Care Research and Review. 374-378.Retrived from https://doi.org /10.15520/mcrr.v3i6.98.

Dang CN, Boulton A.J. 2003; Changing perspectives in diabetic foot ulcer management. Int J Low Extrem Wounds 2:4-12. Retrived from https://doi.org/10.1177/1534734603002001002

F.M. Alsaleh, K.S. AlBassam, Z.K. Alsairafi et al., Knowledge and practice of foot selfcare among patients with diabetes attending primary healthcare centres in Kuwait: A cross-sectional study, Saudi Pharmaceutical Journal, https://doi.org/10.1016/j.jsps.2021.04.006.

George H, Rakesh PS, Krishna M, Alex R, Abraham VJ, George K, et al. Foot care knowledge and practices and the prevalence of peripheral neuropathy among people with diabetes attending a secondary care rural hospital in southern India. J Fam Med Primary Care 2013; 2:27-3.

Kurian.B,Qurieshi M.N , Ganesh.R, Leelamon.K. 2016; A community based study on knowledge of diabetes mellitus among adults in a rural population of Kerala. Intl J of Non-communi Dis. 1, 59-64. Retrived from https://doi.org/10.4103/2468-8827.191925

Mathers CD, Loncar D. 2006 ; Projections of global mortality and burden of disease from 2002 to 2030. PLoS Med 3, e442. Retrived from https://doi.org/10.1371/journal.pmed.0030442

Mishra SC, Chhatbar KC, Kashikar A, Mehndiratta A, 2021 Diabetic foot, BMJ; 359:1:1-7.

Mohan.V, Sandeep.S, Deepa.R, Shah.B, Varghese.C. 2007; Epidemiology of type 2 diabetes: Indian scenario.Indian J Med Res. 175,217-30.

Nicolucci A, Kovacs Burns K, Holt RIG, Comaschi M, Hermanns N, Ishii H, et al. 2013; Diabetes Attitudes, Wishes and Needs second study (DAWN2TM): Crossnational benchmarking of diabetes-related psychosocial outcomes for people with diabetes. Diabet Med J Br Diabet Assoc. 30(7), 767-77. Retrived from https://doi.org/10.1111/dme.12245

Pinzur MS, Slovenkai MP, Trepman E,Shields NN, 2005; DiabetesCommittee of American Orthopaedic Foot and Ankle Society.Guidelines for diabetic foot care: Recommendations endorsedby the diabetes committee of the American orthopaedic foot and ankle society. Foot Ankle Int 26:113-9. Retrived from https://doi.org/10.1177/107110070502600112

Pitchai P, Joshi J. 2015; Knowledge and practice of foot care amongst diabetics in India: comparison between urban and rural setting- a reality check. Int J Health Sci Res. 5(4):181-189. 
Saurabh S, Sarkar S, Selvaraj K, Kar SS, Kumar SG, Roy G. 2014; Effectiveness of foot care education among people with type 2 diabetes in rural Puducherry, India. Indian J Endocr Metab 18 :106-10. Retrived from https://doi.org/10.4103/2230-8210.126587

Sharma K. 2013; Burden of non-communicable diseases in India: Setting priority for action. Int J Med Sci Public Health. 2,7-11. Retrived from https://doi.org/10.5455/ijmsph.2013.2.7-11

Shrivastava PS, Shrivastava SR, Ramasamy J (2015) An Epidemiological Study to Assess the Knowledge and Self Care Practices among Type 2 Diabetes Mellitus Patients Residing in Rural Areas of Tamil Nadu. Biol Med S3: 002. doi: 10.4172/0974-8369.S3-002. Retrived from https://doi.org/10.4172/0974-8369.1000s3002

Sivapriya.T , John. 2019; S A Cross Sectional Study on Knowledge, Attitude and Practice of Type 2 Diabetes Mellitus Subjects about Diabetes, JKIMSU. 8(1), 14-21.

Stockl K, Vanderplas A, Tafesse E, Chang E. 2004; Costs of lower-extremity ulcers among patients with diabetes. Diabetes Care $27: 2129-34$. Retrived from https://doi.org/10.2337/diacare.27.9.2129

Subhashini S, Shah PB. 2016; Awareness and practice regarding foot self-care among patients of known type 2 diabetes mellitus in a rural area India. Int J Community Med Public Health 3 :861-4. Retrived from https://doi.org/10.18203/2394-6040.ijcmph20160917

Vighnesh CS, Rangaswamy S, Arthi M. 2019 ; Awareness and practices of foot care in patients with diabetes mellitus in an urban area in Puducherry. Galore International Journal of Health Sciences \& Research. 4(3) : 150-157.

WHO. 2016; Global report on diabetes: A summary.Int J Noncommun Dis 1-3. Retrived from https://doi.org/10.4103/2468-8827.184853. 